\title{
NIH task force to examine 'culture' of discrimination
}

Washington. Saying that "where there's smoke there's usually fire", the director of the US National Institutes of Health (NIH), Bernadine Healy, has formed a task force to examine racial and sexual discrimination on campus in Bethesda, Maryland.

The task force is Healy's response to recent public demonstrations by two civil rights groups of their unhappiness with NIH's handling of a report by an outside consultant that found evidence to support allegations of discrimination and favourit-

\section{IMAGE UNAVAILABLE FOR COPYRIGHT REASONS}

\section{Healy moves quickly.}

ism by senior managers in the division of acquisitions management (see Nature 363 , 6 ; 1993). It is an attempt to erase the negative publicity that NIH has received for its failure to address the problems raised in the seven-month-old report by showing that $\mathrm{NIH}$ is concerned about the issue and can move quickly.

Speaking to some $200 \mathrm{NIH}$ employees at a rally last week on the lawn in front of her office, Healy said that the report revealed activity that is not acceptable. NIH already has an Office of Equal Opportunity (OEO) to handle complaints from individuals about problems on the job, but the new task force is expected to examine "environmental" issues at NIH that contribute to sexual and racial discrimination at all levels.

The task force will be led by John Diggs, head of the extramural research programme and the highest-ranking African American at $\mathrm{NIH}$, but details relating to its membership, scope and duration have yet to be worked out. Diggs, who is leaving NIH in a month to become vice president for biomedical research at the Association of American Medical Colleges (AAMC), was asked to chair the group only minutes before Healy spent an hour with representatives of the National Association for the Advancement of Colored People (NAACP) and the NIH chapter of Blacks in Government (BIG). The groups held a press conference two weeks ago to discuss the report and convened last week's lunch-time rally.

Vincent Thomas, president of BIG, says that the task force is "a very positive thing" and that its creation sends a signal to NIH managers that "discrimination will not be tolerated". Thomas, who will serve on the panel along with both senior NIH administrators and rank-and-file employees, praised Healy for her willingness to deal with the issue but says that it is too early to predict the outcome of its deliberations. Healy is leaving NIH at the end of June and it could be several months before a successor is named and takes up the post.

Diggs, who had not yet read the consultant's report when Healy tapped him, said that he hopes the task force "will develop strategies to redress grievances" quickly. "A lot can happen if you let a case drag on for seven years", he says, referring to the length of time since the first complaints were brought against managers in the procurement office. At the same time, he says, some employees have failed to follow up their initial complaints with sworn statements and other documentation because they fear reprisals from superiors.

Last week, the NAACP tried to remedy that situation by sponsoring a 'complaints fair' to collect additional evidence of discrimination on the job. NIH employees were encouraged to bring evidence documenting their complaints and were then matched with local attorneys who have agreed to represent them without fee. OEO director Diane Armstrong says that the complaints will be processed as quickly as possible, taking advantage of a recent fourfold increase in her staff.

In a related matter, an OEO advisory committee of black employees is petitioning NIH to block the planned move of OEO offices from the main campus to satellite offices several miles away. The petitions claim that the move, which is being made next month to bring Armstrong's staff together on the same floor, would make it harder for employees to present their complaints and would require them to receive permission to leave the campus from the same supervisors who might be the subject of their complaint.

Armstrong says that any employee may visit her office but that permission must be obtained whenever someone leaves the work place. "I don't see our new office as a barrier", she says. "In fact, some people have told me that they prefer us to be in a less conspicuous location." Jeffrey Mervis

\section{Changes urged in US government hiring practices}

Washington. With the current recession making public service an attractive alternative to the private sector, a new report on what the US government must do to attract and retain the best scientific talent addresses a problem that - at least for now - does not exist. But if the time to fix a roof is when the sun is shining, then the report by the $\mathrm{Na}$ tional Academy of Sciences provides useful advice on what the federal government can do to avoid the inevitable next flood of complaints.

Three important improvements would be delegating hiring authority to those at the work site, easing restrictions on - although not necessarily increasing -- starting salaries and making increases contingent on performance ratings. The changes, according to the report by the academy's National Research Council, would make the government more able to compete with industry for qualified scientists.

Although economic conditions have deteriorated since the study was started two years ago and US President Bill Clinton has proposed a one-year freeze on federal salaries, money is not the key to better recruiting and retention practices, says the academy's Alan Fechter. "We are talking about creating tools for good management", Fechter says. "If hiring takes less time and generates less paper work, then we've accomplished something."

Several US agencies have conducted demonstration projects to test such management changes. At the National Institute of Standards and Technology (NIST), project chief Allen Cassady says that streamlined procedures that were introduced in 1988 shortened the hiring process and identified more highly qualified people. "We don't have to match industry dollar for dollar, since the work here is interesting", he says. "We just need to close the gap enough that people feel they can afford to move." NIST maintained a level personnel budget during its project by hiring fewer people than it could have done.

The academy's report recommends a process in which agencies are allowed to design appropriate changes after consulting other departments and in conjunction with the Office of Science and Technology Policy and the Office of Personnel Management. In the longer term, the report suggests that the government should develop a database to monitor the way in which policy changes affect the work force, evaluate its policies every four years and create a category specifically for scientists and engineers. Both agencies say that the report is being given serious consideration.

Jenna Roberts 